\title{
A REALIDADE DA MORFOLOGIA ENDODÔNTICA NAS RAIIZES VESTIBULARES FUSIONADAS DOS SEGUNDOS MOLARES SUPERIORES
}

\author{
Nicolau Fonseca Milano* \\ Carlos Augusto Gomes da Silva * \\ Luiz Eduardo Schroeder de Lima**
}

MILANO, Nicolau Fonseca et alii. A realidade da morfologia endodôntica nas raízes vestibulares fusionadas dos segundos molares. Revista da Faculdade de Odontologia, Porto Alegre, 25:33-8, 1983.

Descritores: Endodontia - Anatomia dentária - Canal radicular, Terapia.

\section{RESUMO}

Considerando que a literatura sobre o assunto não é suficientemente clara, os autores resolveram estudar a morfologia interna (endodôntica) da região vestibular dos segundos molares superiores quando as raízes vestibulares se apresentam fusionadas.

A idéia partiu da possibilidade de, face a raízes fusionadas, o número de canais vir a ser de um ou dois.

O trabalho foi elaborado em 59 segundos molares superiores com as raízes vestibulares fusionadas, extraídos pelas mais diversas razões, sem a preocupação de idade, cor ou sexo do paciente.

Após a secção transversal da coroa a nivel do colo anatômico, os canais foram percorridos com instrumentos en- dodônticos buscando suas desobstruções. A seguir foi introduzida tinta nankin nos canais para melhor evidenciação. Finalmente foram feitos desgastes com pedras montadas, das raízes vestibulares, no sentido cérvico-apical, desde o assoaIho da câmara pulpar até os forames.

Completada a parte experimental foi possivel a diferenciação dos casos em quatro grupos, segundo o número de canais e o número de forames.

\section{INTRODUÇÃO}

O segundo molar superior, além de seu posicionamento posterior na cavidade oral, pode apresentar uma outra dificuldade para o tratamento endodôntico. É sabido que em $50 \%$ dos casos, podemos encontrar um fusionamento total

* Professor Titular de Endodontia da Faculdade de Odontologia da UFRGS.

**Cirurgiões Dentistas colaboradores. 
ou parcial das raízes vestibulares, devido ao grande achatamento no sentido mésio-distal. Em conseqüência, encontramos uma grande variedade de forma e número de canais nesta região.

\section{PROPOSIC̣ÃO}

Este trabalho se propõe a esclarecer um pouco mais esté ponto ainda obscuro da endodontia. Nele estudaremos a região vestibular do segundo molar superior, uma vez que a região palatina não apresenta maior dificuldade devido a sua constância.

\section{REVISÃO BIBLIOGRÁFICA}

Para o caso de segundo molar superior com raízes vestibulares fusionadas, nos quais nos interessou o número e morfologia dos canais, foi feita a seguinte revisão bibliográfica:

Maisto ${ }^{10}$, Lascala ${ }^{8}$ e Coolidge 2 ao citarem Hess, afirmam que a morfologia do segundo molar superior se assemelha à do primeiro molar superior ou seja: 3 raízes, sendo que em 54\% destes casos possuem 2 canais na raiz mésiovestibular e $46 \% 3$ canais.

Já Paiva ${ }^{11}$, que também cita a semeIhança com o primeiro molar superior, fala em apenas 3 ou 2 canais, isto quando houver fusionamento das raízes vestibulares, dando origem a 1 canal. Da mesma opinião é Kuttler ${ }^{7}$, que afirma que ao haver o fusionamento das raízes vestibulares $(27,2 \%)$ ocorre apenas 1 canal nestas raízes.

Mário Leonardo 9 afirma a existência de 3 canais (semelhante ao 1 ? molar superior), mesmo no caso de fusionamento ( $50 \%$ dos casos), considerando rara a duplicação dos canais na raiz mésio-vestibular.

Os autores acima citados, $10 ; 8$; $2 ; 1 ; 9 ; 7$; e ${ }^{11}$ são unânimes ao afirmar a possibilidade do fusionamento das raízes vestibulares.

Já De Deus ${ }^{3}$, Della Serra ${ }^{4}$ e Pucci ${ }^{12}$ salientam o fusionamento de uma das raízes vestibulares com a palatina ou entre si.

De Deus ${ }^{3}$ estudando 100 exemplares de dentes permanentes jovens apresentou um percentual de $25 \%$ de raízes fusionadas e $20 \%$ de fusionamento total ou parcial das 3 raízes. O mesmo autor, ao afirmar que $50 \%$ dos segundos molares superiores tem 2 canais na raiz mésio-vestibular, chega à seguinte estatística: $18,3 \% 2$ canais e 2 foramens; $20,0 \%$ 2 canais que se unem no $1 / 3$ médio; $11,7 \% 2$ canais que se unem no $1 / 3$ apical.

Pucci $^{12}$ ao estudar um total de 191 segundos molares superiores, encontrou uma percentagem de $46,3 \%$ de dentes com raízes fusionadas em 4 grupos: $19,4 \%$ fusionamento entre as raizes vestibulares; $7,2 \%$ com fusionamento da raiz mesial com a palatina; $5,2 \%$ com fusionamento da raiz distal com a palatina e $12,5 \%$ total fusionamento das raízes.

Semelhante resultado apresentou Ingle 6 ao encontrar um total de $46 \%$ de segundos molares superiores com fusionamento de uma das raízes.

Della Serra ${ }^{4}$ apresenta estatísticas de vários autores, onde poderemos constatar uma grande controvérsia quanto aos resultados encontrados, prova disto citamos: Fabian encontrou - fusionamento das raízes Mv+P 25,9\%; Dv+P $1,4 \%$; Vs+P $4,8 \%$ e total fusionamento $8,9 \%$. Hjelman-Mv+P 5,7\%; Dv+P 8,2\%; 
Vs+P $13,9 \%$ e total fusionamento $1,9 \%$. Jøegensen - Mv+P 15,0\%; Dv+P 1,3\%; Vs+P $14,0 \%$ e total fusionamento $15,0 \%$. Taviani encontra os mesmos resultados que Jøegensen exceto na Dv+P 0,3\%. De Terra encontra somente o fusionamento Vs+P 3,5\%.

\section{MATERIAL E MÉTODO DE TRABALHO}

Foram utilizados segundos molares superiores extraídos, cariados ou não, com algumas das raízes fusionadas (preferencialmente as vestibulares), já que os dentes com diferenciação radicular em nada nos auxiliariam no presente estudo. Tal escolha foi feita independentemente de idade, sexo, cor, etc.

0 método de trabalho desenvolvido nestas peças dentárias foi o seguinte:

Inicialmente, com disco de carborundum, foi feito um corte transversal na altura do colo, a fim de observar-se o assoalho da câmara pulpar e as entradas dos canais radiculares. A seguir procedeu-se ao alargamento dos canais ou canal vestibular com limas tipo Kerr com auxílio de EDTA.

Conseguido acesso em toda a extensão, introduzimos tinta nanquim preta nos canais até os foramens, após o que o dente era guardado pelo espaço de 48 horas. Decorrido este período, com auxílio de uma pedra montada procedeuse ao desgaste das raízes vestibulares no sentido cérvico-apical desde o assoalho da câmara até os foramens, evidenciando-se assim nitidamente, o trajeto do(s) canal(is) destacados pela tinta nanquim.

Após, na tentativa de evidenciar radiograficamente a posição destes canais, foram colocados instrumentos endodôn- ticos sobre os mesmos, e com o auxílio de fitas adesivas aí fixados e radiografados.

\section{APRESENTAÇÃO DOS RESULTA- DOS}

Dos 59 dentes com raízes vestibulares fusionadas, examinadas pelo método anteriormente descrito, chegamos aos seguintes resultados.

Os segundos molares superiores, quando com fusionamento nas raízes vestibulares, podem ser classificados em 4 grupos, a saber:

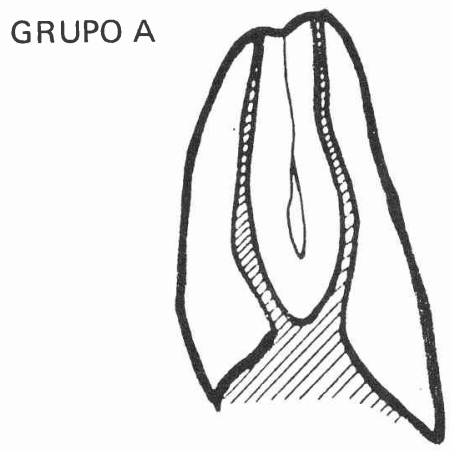

A - do is canais distintos com do is foramens distintos.

36 casos, $61,02 \%$

GRUPO B

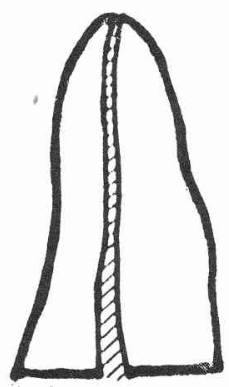

B - um canal distinto com um foramen único.

12 casos, $20,34 \%$ 


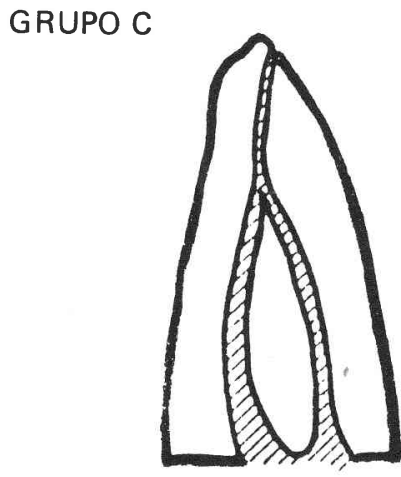

C - dois canais distintos com um único foramem.

9 casos, $15,26 \%$
GRUPO D

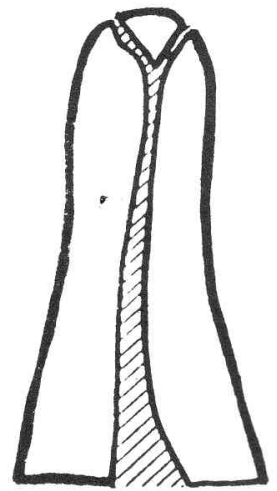

D - um canal com dois foramens.

2 casos, 3,38\%

TABELA COMPARATIVA

\begin{tabular}{ccc}
\hline GRUPOS & N. DE CASOS & \% DE CADA GRUPO \\
\hline A & 36 & 61,02 \\
B & 12 & 20,34 \\
C & 9 & 15,26 \\
D & 2 & 3,38 \\
\hline TOTAL & 59 & 100,00 \\
\hline
\end{tabular}

\section{RESUMO E DISCUSSÃO}

Num total de 59 segundos molares superiores estudados, com fusionamento das raízes vestibulares, foram encontrados 4 grupos de dentes quanto à morfologia dos canais vestibulares.

- grupo A: 2 canais, 2 foramens

- grupo B: 1 canal, 1 foramen

- grupo C: 2 canais, 1 foramen

- grupo D: 1 canal, 2 foramens

Foi feita uma vasta revisão da literatura onde encontrou-se grande diversidade de estatística quanto à morfologia do segundo molar superior.
Certas vezes ficava uma certa dúvida se o autor citava raízes ou canais, por exemplo: é comum o fusionamento das raízes mésio-vestibulares e a palatina, contudo não se sabe se há o fusionamento dos canais destas raízes.

\section{CONCLUSÃO}

Dos resultados obtidos com o método de trabalho utilizado é lícito concluir-se o que segue:

Apesar dos autores consultados afirmarem que as raízes vestibulares dos segundos molares superiores apresen- 
tam-se fusionadas em $46 \%$, o mesmo não ocorre com a distribuição topográfica dos canais radiculares existentes nestas raizes, senão que variam com as seguintes freqüências:

1 - Canal único em toda a extensão $20,34 \%$

1.2 - Canal único divergindo no $1 / 3$ médio ou apical $-3,38 \%$

2 - Canais autônomos em toda a extensão $-61,02 \%$

2.1 - Canais que fusionam no $1 / 3$ médio ou apical - 15,26\%

\section{SUMMARY}

There is doubts about the endodontic morphology of the buccal region of the upper second molar when it showed the buccal roots fusioned.

This paper was performed to determine the number of root canal when the tooth presents the buccal roots fusioned. Fifthy nine upper second molars that presented the buccal roots fusioned, extracted for different reasons without atention to age, sex or race, was used.

After the cross-cuting at the anatomic neck the root canal was opened by endodontic instruments and painted with black ink, for best visualisation. Finaly the roots were sliced with burs in the cervico-apical direction.

We found four groups of teeth based in the number of root canal and/ or apex foramen. 


\section{REFERÊNCIAS BIBLIOGRÁFICAS}

1. ARAÚJO, Mário J. - Anatomia e biomecânica dos canais radiculares. Rev. Bras. Odont., Rio de Janeiro, 14(83):229-55, set./out. 1956.

2. COOLIDGE, Edgard D. \& KESEL, Robert G. - Anatomía del los conductos radiculares en relacion a la remocion pulpar y la obturacion. In: Manual de endodontologia. - Buenos Aires, Ed. Bibliográfica Argentina, 1957. cap. 7, p. 163-77.

3. DE DEUS, Quintiliano Diniz - Topografia da cavidade pulpar e do periapice. In:__ Eridodontia. 2.ed. Rio de Janeiro, Guanabara Koogan, 1976. cap. 3, p.71-73.

4 DELLA SERRA, Otávio \& FERREIRA, Flávio Vellini. - Dentes molares permanentes. In. 1976. cap. 7, p.146-7.

5. GROSSMAN, Louis I. - Anatomia da cavidade pulpar. In: Endodontia prática. 8.ed. Rio de Janeiro, Guanabara Koogan, 1976. cap. 11, p. 176.

6. INGLE, John I. \& BEVERIDGE, Edward E. - Preparação da cavidade endodôntica. In: . Endodontia. 2.ed. Philadelphia, Lea \& Febiger, 1976. cap. 3, p. 146-7.

7. KUTTLER, Yury. - Anatomia topografica de la cavidad pulpar. In: Endodoncia practica. México, Ed. A.L.P.H.A., 1961, cap. 2, p.17-34.

8. LASALA, Angel. - Anatomia pulpar y de los conductos radiculares. In:_ Endodonia. 2.ed. Caracas, Cromotip, 1971. cap. 1, p.5-19.

9. LEONARDO, Mário Roberto - Aspectos anatômicos da cavidade pulpar; relações com tratamento endodôntico. In: LEONARDO, M. R. et alii - Endodontia; tratamento dos canais radiculares. São Paulo, Ed. Médica Pan Americana, 1982. cap. 3, p. 134.

10. MAISTO, Oscar A. - Anatomia quirurgica y preparacion de los condutos radiculares. In: Endodoncia. Buenos Aires, Mundi, 1967. cap. 9, p. 139-62.

11. PAIVA, José Gustavo de \& ALVARES, Sérgio - Preparo do canal. In: Endodontia. 2.ed. São Paulo, Atheneu, 1979. p. 182-205.

12. PUCCl, Francisco M. \& REIG, Robert - Morfologia y topografia dentarias. In:_ Condutos radiculares; anatomia, patologia y terapia. Montevideo, Ed. Medico Quirurgica, 1944. v.1, cap. 3, p.144-247. 